\title{
OS OBJETOS GRÁFICOS DE MIRA SCHENDEL: O SILÊNCIO DA FALA NA IMAGEM'
}

Mira Schendel's Objetos gráficos: the silence of speech in image Los Objetos gráficos de Mira Schendel: el silencio del discurso en la imagen

> Thiago Grisolia Fernandes (Universidade Federal do Rio de Janeiro, Brasil)*

FERNANDES, Thiago Grisolia. Os Objetos gráficos de Mira Schendel: o silêncio da fala na imagem. Revista Poiésis, Niterói, v. 23, n. 39, p. 155-169, jan./jun. 2022.

Este documento é distribuído nos termos da licença Creative Commons Atribuição-Não Comercial 4.0 Internacional (CC-BY-NC) (C) 2022 Thiago Grisolia Fernandes. Submetido: 10/3/2021; Aceito: $25 / 5 / 2021$
RESUMO Este artigo propõe uma análise da série Objetos gráficos ( 1967/1973) de Mira Schendel, artista nascida na Suíça e radicada no Brasil, a partir da ideia do silêncio e da ausência implicados na linguagem. Três elementos principais são abordados nesta análise: a materialidade da letra, a transparência do suporte de acrílico e papel de arroz e a existência de várias camadas na obra, que garantem uma profundidade à mesma. A partir da leitura de autores como Haroldo de Campos, procuramos ainda inserir o trabalho de Mira Schendel dentro de um campo ampliado da poesia, esgarçando as fronteiras entre palavra e imagem no contemporâneo. PALAVRAS-CHAVE Mira Schendel; Objetos gráficos; silêncio; ausência.

ABSTRACT This article proposes an analysis of the series Objetos gráficos (1967/1973) by Mira Schendel, an artist born in Switzerland and based in Brazil, based on the idea of silence and absence implied in language. Three main elements are addressed in this analysis: the materiality of the letter, the transparency of the acrylic and rice paper support and the existence of several layers in the work, which guarantee its depth. Based on the reading of authors like Haroldo de Campos, we also try to insert Mira Schendel's work into a broader field of poetry, blurring the boundaries between word and image in the contemporary.

Keywords Mira Schendel; Objetos gráficos; silence; absence.

RESUMEN Este artículo propone un análisis de la serie Objetos gráficos (1967/1973) de Mira Schendel, artista nacida en Suiza y afincada en Brasil, a partir de la idea de silencio y ausencia implícita en el lenguaje. En este análisis se abordan tres elementos principales: la materialidad de la letra, la transparencia del soporte de acrílico y papel de arroz y la existencia de varias capas en la obra, que garantizan su profundidad. A partir de la lectura de autores como Haroldo de Campos, también intentamos insertar la obra de Mira Schendel dentro de un campo más amplio de la poesía, difuminando los límites entre palabra e imagen en lo contemporáneo. PALABRAS CLAVE Mira Schendel; Objetos gráficos; silencio; ausencia.

* Thiago Grisolia Fernandes é doutorando no Programa de Pós-Graduação em Ciência da Literatura da Universidade Federal do Rio de Janeiro. E-mail: goathigrisolia@yahoo.com.br. ORCID: https://orcid.org/0000-0002-0856-8528.

Revista Poiésis, Niterói, v. 23, n. 39, p. 155-169, jan./jun. 2022. [DOl: hittps://doi.org/10.22409/poiesis.v23i39.49097]. 
INTRODUÇÃO

Mira Schendel foi poeta, antes de se estabelecer como artista visual, uma das mais instigantes do Brasil do século XX, especialmente pela dificuldade - e pela falta de necessidade - de incluí-la em alguma vertente da história da arte, de filiá-la a alguma tendência estilística, embora isso tenha sido tentado, com mais ou menos sucesso. Haroldo de Campos, por exemplo, contrariando o movimento mais usual da crítica, que é o de tentar inseri-la em uma vertente mais ligada ao construtivismo e a algumas questões do Concretismo, em entrevista a Sônia Salzstein, afirma que lateral, apenas para chegar aí, onde sua atividade de poeta se revela insuficiente para dar conta de suas questões artísticas. Caberá lembrarmo-nos de seu nascimento em Zurique, na Suiça, em 1919, sua formação intelectual, já em artes, mas também em filosofia e teologia, na Itália, suas viagens em fuga da perseguição nazista, que a levaram a Sarajevo, Roma e, finalmente, em 1949, a Porto Alegre, no Brasil, país onde instalou-se definitivamente até a sua morte, em 1988. E, aqui, Mira inicia um diálogo com intelectuais e poetas importantes, como o físico Mário Schenberg e o poeta Haroldo de Campos, e desenvolve seu trabalho artístico, ao mesmo tempo em que leciona e publica poemas.

Seus poemas, tais como eram publicados no início aqueles com quem Mira teria mais ligação seriam o Hélio Oiticica, por alguns aspectos específicos, ligados ao trabalho mais pictural que ele realizou, e a Lygia Clark, por determinados esvaziamentos da forma que marcam alguns de seus objetos. Eu acho que os três formam uma constelação de artistas [CAMPOS, 1996, p. 241].

Consideramos fundamental iniciar este pensamento a respeito do trabalho de Mira Schendel, mais especificamente a respeito da série Objetos gráficos, realizada pela artista entre 1967 e 1973, com a afirmação de que ela foi poeta.

Por iniciar deste modo, é recomendável recorrer à sua biografia, mas apenas de maneira breve e de sua vida no Brasil, são difíceis de serem encontrados, e não nos caberia reproduzi-los aqui. O diálogo com a poesia que nos leva a iniciar este ensaio afirmando que Mira Schendel foi poeta se revelará manifesto ao longo de toda a sua trajetória artística, e se funda muito mais sobre uma perspectiva ampliada de poesia [uma perspectiva que seguiria as pistas oferecidas por Rosalind Krauss e indicaria um campo ampliado da poesia], que considera, inclusive, a poesia muito mais a partir de sua negatividade, de seu coeficiente silencioso; a partir daí, interessa observar que, já do nascedouro, a produção plástico-poética 
de Mira articula a palavra, a imagem e o silêncio através de um reviramento da linguagem, como procuraremos demonstrar a seguir.

Os Objetos gráficos evocam, de um modo muito singular, a ideia de vazio que permeia todo o trabalho de Mira, e por isso trataremos especificamente de tais trabalhos neste texto. Maria Eduarda Marques aponta-nos o seguinte:

A noção de vazio foi uma constante na obra de Mira, presente nas pinturas e, mais intensamente, nos desenhos que veio a realizar. ' $O$ espaço vazio me comove profundamente', disse ela. É o vazio do sujeito imanente, no limiar de sua existência e expressividade, imerso 'nel vuoto del mondo' [no vazio do mundo] [...]. O vazio que se apresenta em suas pinturas não é apenas ausência de objetos representados no plano: evoca a ideia de uma negatividade produtiva [...]." [MARQUES, 2011, p. 19-20]

Trata-se, no trabalho em questão, de uma série de telas que "flutuam" pelo espaço expositivo presos por fios de náilon [como pode ser visto na figura 1]; as telas consistem em uma série de letras, algarismos e outros signos gráficos, datilografados ou adesivados, e outros símbolos não-gráficos, mas que remetem a espécies de rabiscos, manuscritos por Mira, dispostos sobre uma folha de papel de arroz prensada por duas camadas de acrílico, sobre as quais também são inseridos alguns símbolos. A cor de tudo isto é escura, quase preto-e-branco, ou sépia; os símbolos, como bem apontado por Ricar- do Nascimento Fabbrini, "são discretos, diminutos" [FABBRINI, 2002, s/p]. As letras pairam, flutuam pelo espaço; há profundidade, dada pelas camadas que se sobrepõem [letras sobre acrílico sobre letras sobre papel de arroz sobre letras sobre acrílico sobre letras]; e há, sobretudo, transparência.

O que salta aos ol hos nesses trabalhos de Mira são esses três elementos fundamentais: a presença da letra, dissociada da formulação de um vocábulo; a profundidade, embora pareça tratar-se de um plano; e a transparência da composição, que Ihe confere certa fragilidade, certa evanescência. Do intervalo entre esses elementos, entre essas exigências fundamentais dessas telas, portanto do silêncio que, essencialmente, há nessa composição, emerge o sentido que nos será caro em sua análise. 


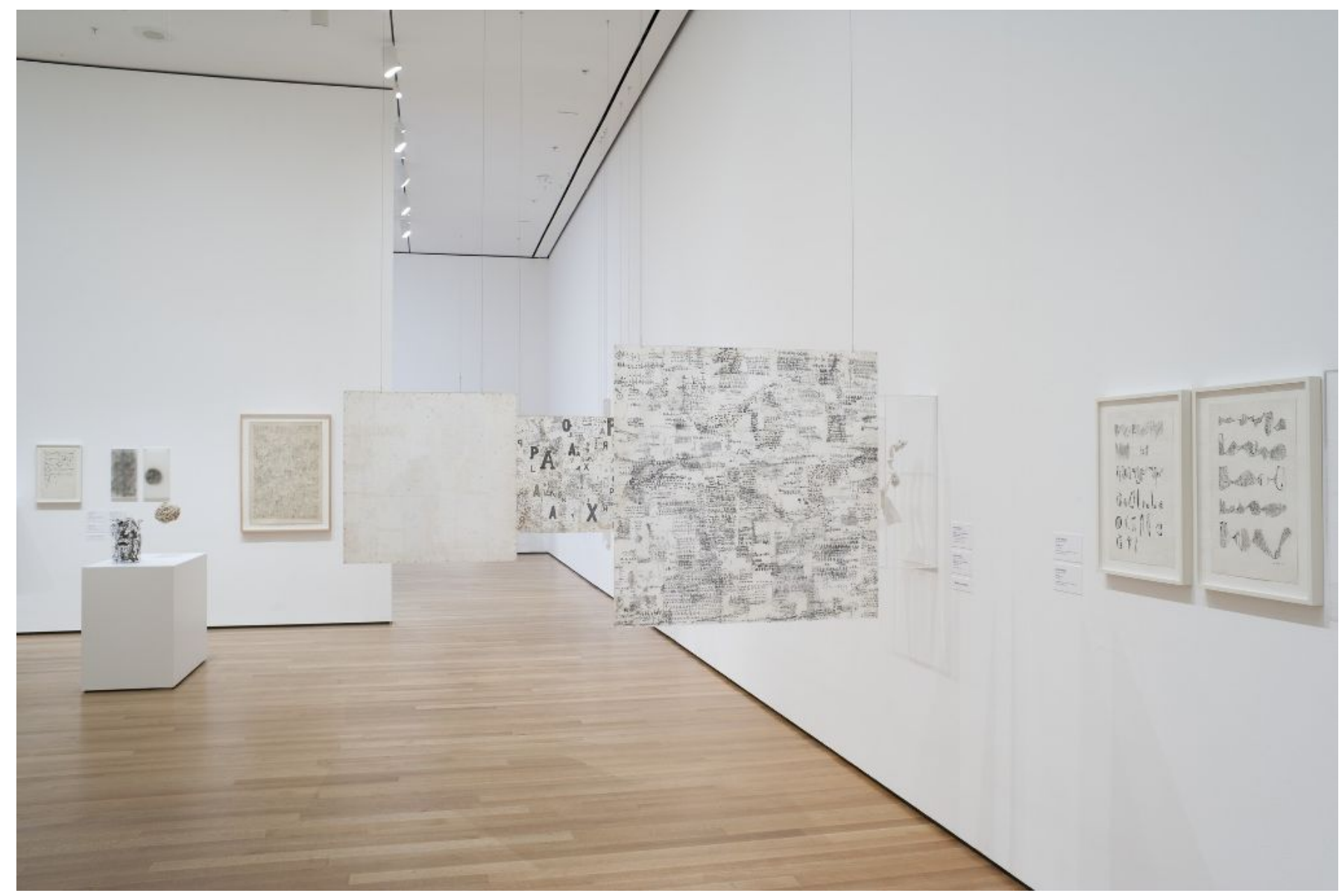

Fig. 1 -Vista da exposição Tangled alphabets: León Ferrari and Mira Schendel, MoMA, 2009, com alguns trabalhos da série Objetos gráficos em destaque. [Fotografia de Jonathan Muzikar]

[Fonte: https://www.moma.org/calendar/exhibitions/299/installation_images/3951\#, acesso em 05/03/2021.] 
espectadores, fragilizados pela nossa necessidade de racionalizar, de pôr em palavras, de dar nossa palavra para tornar em verdades as coisas, de sa-

A "poética da letra", trabalhada pela artista Helena Trindade em ensaio que recebe justamente esse título, nos dá um bom caminho para pensar a letra tornada imagem, e a decorrente relação que se torna manifesta entre a escrita e a visualidade: ber o mundo através da palavra, que as ordenemos; que as coloquemos em relação; que as utilizemos para construir um sentido por vir; que imaginemos que há uma palavra oculta, por formar-se, por revelar-se no meio daquele turbilhão de ausências; que há talvez uma sentença primordial onde tudo o que vemos é ausência, onde só o que se nos mostra é "pura entropia" [FABBRINI, 2002, s/p], como diria o pesquisador Ricardo Fabbrini a respeito da obra de Mira. Não nos parecerá tentador achar justamente a palavra "palavra" no canto direito do Objeto mostrado a seguir [figura

É interessante observar o trabalho de Mira por essa perspectiva; buscar o vazio daquelas letras, que não foi abolido delas quando receberam o novo estatuto de imagens; observar que sua presença não completa a imagem, mas a "des-completa". Mas a letra talvez nunca possa vir a ser um signo puramente visual, plástico, principalmente no trabalho de Mira. Isso porque, sobretudo nesses trabalhos, pelo fato de as letras estarem aproximadas umas das outras, avizinhadas, há um chamamento ao sentido, à palavra, ao verbo. Essa composição, por mais que se quisesse puramente visual, pede a nós,
2], como se se tratasse de um jogo, de um caça-palavras, de um desafio cartesiano, e "desvendar", assim, o sentido da obra?

página seguinte

Fig. 2 - Mira Schendel, série Objetos gráficos, 1997/1973

Tipografia, grafite e óleo sobre papel entre placas de acrílico tipografadas, $100 \times 100 \mathrm{~cm}$.

[Fonte: https://www.moma.org/collection/works/108826, acesso em 05/03/2021.] 
Mesmo sabendo que "tornada objeto, a letra fica opaca e resiste ao sentido" [RIVERA, 2009, p. 125], nós quase nunca resistimos a atribuir-Ihes sentidos. Mesmo sabendo que

a partir de sua aparente irredutibilidade, a letra pode ser pensada como o resultado de um processo radical de essencialização e adensamento da linguagem que se presta muito bem a uma visualidade de concisão e economia de meios [TRINDADE, 2013, p. 23],

e que "o exemplo mais puro do significante é a letra" [LACAN apud TRINDADE, 2013, p. 23], ainda assim não cessamos de buscar o significado como duplo do significante, mesmo do mais "puro" deles, de não aceitar da linguagem seu adensamento e fazê-la espargir-se, transbordar. Resistir a isso seja talvez uma chave de entrada fundamental para o trabalho de Mira Schendel e por isso, pensando esse trabalho, Vilém Flusser afirma: "São as letras em formação que demandam o significado. São os enxames de letras que demandam o sentido. São as metamorfoses de letras que demandam as regras do jogo do pensamento" [FLUSSER, 1996, p. 265].

Mas é interessante retornar à ideia de que a letra, "tornada objeto, [...] fica opaca e resiste ao sentido" $\square$. É dessa opacidade, dessa resistência ao sentido advinda da opacidade, que nasce o elemento mais forte, mais importante para este estudo presente nos Objetos gráficos. Porque, nesses trabalhos, a letra, "tornada objeto", tem sua opacidade irrevogavelmente contrastada à transparência do suporte em que é colocada. A opacidade da letra tornada objeto põe em jogo a relação entre os três elementos que, acima, afirmamos serem os mais potentes da série de Mira: a presença da letra, a profundidade e a transparência. É porque a letra é opaca que nos damos conta de que os suportes são transparentes; é porque ela é opaca que, vetando a observação das camadas, anuncia a existência das camadas, pela via negativa; e é porque ela é opaca que a vemos, que a percebemos como tal: letra, símbolo gráfico; letra, objeto gráfico. E é porque ela resiste ao sentido que, de seu silêncio, o sentido emerge: e o silêncio é o sentido, ou, como disse Helena Trindade, o vazio é o que ela, a letra, diz.

\section{A TRANSPARÊNCIA, A PROFUNDIDADE}

É preciso resistir ao sentido diante de uma obra como esta, em que fala o silêncio - o silêncio da letra, exigência daquela tela, necessária para compor o todo transparente e profundo [silencioso] de que faz parte. Mas resistir ao sentido talvez não seja renunciar à história, à biografia.

E volta o dado de que Mira Schendel chegou ao Brasil refugiada da perseguição nazista na Europa; 
volta o dado de que Mira nasceu na Suíça, mas viveu na Itália, Bósnia, Brasil; vem o dado de que a guerra é sempre uma experiência-limite para a formulação de qualquer linguagem, pois é aquilo sobre o que nada se pode dizer; é aquilo que interrompe sua enunciação mesma. Certamente nada de sua produção artística completa-se em algum desses dados; mas há que se levar em consideração que há, neles, muito de silêncio, de ausência. Benjamin afirma que os soldados voltaram da Primeira Guerra Mundial em silêncio; a experiência de que se tratava era incomunicável: para ele, "os livros de guerra que inundaram o mercado literário nos dez anos seguintes não continham experiências transmissiveis de boca em boca" [BENJAMIN, 1994, p. 115]. E há uma relação inegável entre o vazio da experiência da guerra e a frieza das letras tipografadas, dos símbolos gráficos que procuram dizer o mundo, porém nada dizem, porque já não podem dizer. Em livro escrito durante a Segunda Guerra, no poema A flor e a náusea, o poeta mineiro Carlos Drummond de Andrade bem declara: "Os homens voltam para casa. / Estão menos livres mas carregam jornais, / e soletram o mundo, sabendo que o perdem". A incomunicabilidade da experiência, que Benjamin, em seu ensaio de 1933, diz ter se tornado estrutural no homem do pós-guerra, e sobre a qual Drummond, em seu A rosa do povo, escrito durante a Segunda Guerra, tão oportunamente escreveu em alguns de seus melhores versos [como o mencionado acima], também é a pontada pela própria Mira como elemento constitutivo de seu trabalho. Contudo, embora compreenda que essa experiência não apenas a experiência da guerra; a experiência, de uma maneira geral - seja incomunicável, ela não a vê sob o prisma da pobreza, como o faz Benjamin, mas exatamente ao contrário. Diz ela:

a vida imediata, aquela que sofro, e dentro da qual ajo, é minha, incomunicável, e portanto sem sentido e sem finalidade. $O$ reino dos símbolos, que procuram captar essa vida [e que é o reino das linguagens], é, pelo contrário, anti-vida, no sentido de ser intersubjetivo, comum, esvaziado de emoções e sofrimentos. Se eu pudesse fazer coincidir estes dois reinos, teria articulado a riqueza da vivência na relativa imortalidade do signo [SCHENDEL, 1996, p. 256, grifo nosso].

E parece-nos que Mira, a seu modo, de fato consegue efetuar essa coincidência: o signo, "relativamente" imortal, ou seja, de alguma maneira a linguagem, que é o reino no qual procura-se captar, para transmitir, a experiência [a própria vida], comunica, em sua obra, justamente o incomunicável: enuncia o que não pode ser enunciado, e portanto é silêncio, e dá a ver o que é invisível. E parece-nos que Mira só consegue fazê-lo, só consegue alcançar essa coincidência do reino da experiência, 
da vida, com o reino dos símbolos, da linguagem, através da transparência, que, na série dos Objetos gráficos, é justamente o que confere a ele a profundidade que citamos. Maria Eduarda Marques, em estudo sobre a obra de Schendel, diz: de imortalizar o fugaz e dar sentido ao efêmero. Para poder fazê-lo é óbvio que devo fixar o próprio instante, no qual a vivência se derrama para o símbolo, no caso, para a letra.

No começo, pensava que para tanto bastava [...] sentar-me a esperar que a letra se forme. Que assuma sua
Na densidade do desenho e das inscrições, a transparência alcançada na montagem do papel sobre o acrílico é fundamental. [...] o papel é prensado por entre duas placas de acrílico, suspensas por fios de náilon, tornando visível a outra face do plano. A hierarquia do olhar é quebrada, conduzindo a uma leitura circular e virtual. Mira explora a possibilidade de acabar com a frente e o verso. Interessava a ela alcançar a simultaneidade do tempo e do espaço. [MARQUES, 2011, p. 27]

Mas a própria Mira elabora melhor o caminho que a fez chegar no acrílico e a potência do acrílico enquanto transparência para seu trabalho. Embora longo, presumimos ser imprescindivel lançar mão deste trecho integralmente. No decorrer de suas palavras, retiradas de uma anotação sem data, sem título, incluída por Sônia Salzstein em volume que organizou sobre a obra de Schendel, podemos observar muitas das coisas que viemos discutindo elaboradas pela própria artista - rica contribuição sobre o papel da letra, da transparência e da profundidade em sua obra.

que me preocupa é captar a passagem da vivência imediata, com toda a sua força empírica, para o símbolo, com toda a sua memorabilidade e relativa eternidade. [...] Reformulando, é esta minha obra a tentativa forma no papel e que se ligue a outras numa escrita pré-literal e pré-discursiva. Mas sentia, desde o início, que isto poderia ter êxito apenas se o papel fosse transparente. Agora sei melhor avaliar porque tinha então aquela impressão: a letra, ao formular-se, deve mostrar o máximo de suas faces, para ser ela mesma.

Surgiu, no entanto, um segundo problema. A sequência de letras no papel imita o tempo, sem poder realmente representá-lo. São simulações do tempo vivido, e não captam a vivência do irrecuperável, que caracteriza esse tempo. Os textos que desenhei no papel podem ser lidos e relidos, coisa que o tempo não pode. Fixam, sem imortalizar, a fluidez do tempo. Por isso, abandonei esta tentativa.

Abandonei, porque descobri o acrílico, que parece oferecer as seguintes virtualidades: a. torna visível a outra face do plano, e nega, portanto, que o plano é plano; $b$. torna legível o inverso do texto, transformando portanto o texto em anti-texto; c. torna possivel uma leitura circular, na qual o texto é centro imóvel e o leitor é móvel. Destarte, o tempo fica transferido da obra para o consumidor, portanto o tempo se lança do símbolo de volta para a vida; $d$. a transparência que caracteriza o acrílico é aquela falsa transparência do sentido explicado. Não é a transparência clara e chata do vidro, mas a transparência misteriosa da explicação, de problemas. [SCHENDEL, 1996, p. 256] 
Portanto, para Mira, está no material a chave para essa leitura de sua obra; não terá sido à toa que Haroldo de Campos, em entrevista, afirmou que Mira "tem esse grande respeito matérico pelos elementos que convoca em seu trabalho" [CAMPOS, 1996, p.

234]. Do acrílico, de sua potência enquanto material, advêm a negação do plano, que é a profundidade em que temos insistido, e a possibilidade de o "inverso" do texto ser lido, gerando a possibilidade mesma de que se experimente a escrita, ou antes o avesso da escrita [a desescrita, poderíamos dizer] com o corpo - e, talvez, trate-se sempre disso; talvez a desescrita, esse avesso de um texto que lhe é constitutivo, só seja experimentado através de uma operação com o corpo, de uma transferência de tempo da obra para o corpo de seu "leitor", de uma "leitura circular" que possibilita que o tempo seja lançado "do símbolo de volta para a vida". E se Benjamin abomina os ambientes de vidro, sob a justificativa de que "eles criaram espaços em que é difícil deixar rastros" [BENJAMIN, 1994, p. 118], Mira Schendel recusa também o vidro, deixa como rastro o vazio que nada tem a ver com a falta, com a "transparência chata do vidro", com sua assepsia demasiada.

Além da opacidade da letra e da transparência do suporte, há no trabalho de Mira Schendel ainda um outro elemento que, sendo a colocação dos dois primeiros em perspectiva, um em relação ao outro, é aquele que nos revela de forma mais contundente a potência da fragilidade, do silêncio e mesmo da ausência implicados em sua obra. Tal elemento nos é oferecido a partir da ideia das camadas. Segundo a própria Mira, a existência de várias camadas em seu trabalho, através de uma das "virtualidades" do acrílico, nega o plano, indica que "o plano não é plano", denuncia a existência de profundidade, por mais que se trate de uma tela. A ideia de profundidade é este terceiro elemento, que a existência de camadas em seus Objetos gráficos revela.

Em toda tela há a existência de camadas, mesmo que seja, minimamente, a da tinta por sobre a tela [mas há, na maioria dos casos, tintas sobre tintas, e, ainda, outros materiais, que têm sido utilizados das formas mais inusitadas na arte de nosso tempo]. E essa existência de camadas, que confere profundidade material à tela [não estamos nos referindo à profundidade virtual, produzida tecnicamente através da perspectiva], é o modo pelo qual se consegue destacar os elementos que compõem o quadro; é pela existência das camadas que o intervalo entre elas, o vazio entre os signos que fazem parte da composição, irrompe, e é a partir de onde o sentido pode se fazer. Nos Objetos de Mira, essa profundidade é apenas mais bem observada, potencializada pelo acrílico; por isso seu silêncio é tão potente, tão forte, tão eloquente. 
Mira Schendel atinge visualmente o ponto onde o silêncio emerge da fala, ainda que sua fala seja apenas, como ela mesma aponta, pré-literal, pré-discursiva; esse ponto que é comum à fala dos poetas. Seu trabalho, portanto, se é que pode ser considerado um poema, só pode ser assim considerado pela via do silêncio, e não da voz; pela via do intervalo, da ausência, e não tanto da presença das letras. E, embora uma parte da crítica não admita seu trabalho enquanto poesia, como Fabbrini, quando afirma que

as 'miragrafias', todavia, não são 'poemas', mas a figuração de um estado anterior ao nascimento das línguas, um regresso ao 'in nato' das letras, dos algarismos e de suas primeiras conexões [FABBRINI, 2002, s/p],

Haroldo de Campos diz o contrário. Afirma a potência poética do trabalho da amiga Mira Schendel em dois momentos importantes. O primeiro deles é na já referida entrevista a Sônia Salzstein, quando declara o seguinte:

Ela tem esse grande respeito matérico pelos elementos que convoca no seu trabalho e, por outro lado, tem o gosto pela escritura. Esta nem sempre é létrica, às vezes não são letras nem palavras; outras vezes aparecem palavras, e o quadro dela já é um poema, um poema-quadro, um quadro-poema. Certas escrituras são traços, são resíduos, são resquícios, são restos que ela deixa no papel, deixa aflorar no papel, deixa percorrer o papel, como se fossem rastros existenciais, ontológicos. [CAMPOS, 1996, p. 234]

O outro momento é quando escreve um poema, publicado originalmente no catálogo Mira Schendel, relativo à exposição da artista no MAM/RJ, em 1966, e republicado no livro organizado por Salzstein, no qual Haroldo consegue captar, com a excelência poética exigida, essa "arte de vazios" de Mira Schendel.

\section{uma arte de vazios}

onde a extrema redundância começa a gerar informação original uma arte de palavras e de quase palavras

onde o signo gráfico veste e desveste vela e desvela súbitos valores semânticos

uma arte de alfabetos constelados

de letras-abelhas enxameadas ou solitárias $a-b-[l i]-a a$

onde o dígito dispersa seus avatares num transformismo que visa ao ideograma de si mesmo que força o digital a converter-se em analógico uma arte de linhas que se precipitam e se confrontam por mínimos vertiginosos de espaço sem embargo habitados por distâncias insondáveis de anos-luz uma arte onde a cor pode ser o nome da cor 
e a figura comentário da figura

para que entre significante e significado

circule outra vez a surpresa

uma arte-escritura

de cósmica poeira de palavras

uma semiótica arte de ícones índices símbolos

que deixa no branco da página seu rastro luminoso

esta arte de mira schendel

entrar no planetarium onde suas composições

se suspendem desenhos estelares

e ouvir o silêncio como um pássaro de avessos

sobre um ramo de apenas

gorjear seus haicais absolutos [CAMPOS, 1996, p. 239]

A "arte de alfabetos constelados" de que fala Haroldo remete à ideia de "constelação", muito cara a este teórico, e que pode ser aplicada ao trabalho de Mira Schendel. Tomada do texto de Eugen Gomringer, Do verso à Constelação - Função e Forma de uma Nova Poesia, essa ideia aparece em diversos de seus textos mais importantes, e refere-se a um modo outro de pensar a poesia, para além do verso tal como é tradicionalmente conhecido; para pensar este modo outro, tanto Gomringer quanto Haroldo de Campos recorrem à escrita ideogrâmica chinesa, cujo método de composição poética, de acordo com Haroldo, via Ezra Pound, é o de “justaposição direta de elementos em conjuntos geradores de relações novas [o que Gomringer, a exemplo de Mallarmé, denomina de constelação]" [CAMPOS, 2006, p. 141].

Evidentemente, a constelação de que falam Gomringer e Campos refere-se à poesia; e a uma poesia necessariamente feita com palavras. Embora partindo

da consideração do instrumento ideográfico como o processo mental de organização do poema em exata consonância com a urgência por uma comunicação mais rápida, direta e econômica de formas verbais que caracteriza o espírito contemporâneo, antidiscursivo e objetivo por excelência [CAMPOS, 2006, p. 142],

e concebendo o poema "como uma unidade totalmente estruturada de maneira sintéticoideogrâmica [todos os elementos sonoros, visuais e semânticos - verbivocovisuais - em jogo]" [CAMPOS, 2006, p. 142], é importante ressaltar que "a constelação é a forma mais simples de organizar a poesia fundada na palavra" [GOMRINGER apud CAMPOS, 2006, p. 141, grifo nosso].

E, como já vimos, a escritura que está em jogo no trabalho de Mira Schendel, ao mesmo tempo em que se aproxima, pela via da ausência, da poesia - pelo menos de sua essência -, não chega a se constituir enquanto poema feito de palavras: 
é uma "escrita pré-discursiva", anterior à formulação de uma palavra que pudesse se colocar em relação a outras, num jogo constelado. O que se coloca em constelação, aqui, não são as palavras, mas, talvez, como no poema de Haroldo, apenas essa "cósmica poeira de palavras", isto é, as letras.

E é no intervalo entre essas letras, como já vimos, que emerge o teor poético de sua obra, deixando "no branco da página seu rastro luminoso". Mais próximas dos ideogramas do que as palavras em caracteres ocidentais, as letras - cada um dos caracteres per se - é que, em seu trabalho, adquirem uma forma. "Não basta afirmar", diz Fenollosa a respeito dos ideogramas, "que cada um deles encerra um determinado corpo de significado prosaico; pois a questão é como pode o verso chinês implicar, enquanto forma, o elemento que distingue a poesia da prosa?" [FENOLLOSA, 1977, p. 121]. A mesma questão se pode colocar em relação às letras de Mira, na composição não de um verso poético, mas de uma tela que encerra um enunciado potencialmente poético. Nesses objetos gráficos, os alfabetos são constelados, as letras são abelhas enxameadas, que fazem ouvir seu silêncio como um pássaro de avessos.
Colocando em questão a ideia de que o pensamento, naturalmente, ainda segundo Fenollosa, "é sucessivo, não em virtude de algum acidente ou fraqueza de nossas operações subjetivas, mas porque as operações na Natureza são também sucessivas" [FENOLLOSA, 1977, p. 121], Mira, com suas letras não sucessivas, mas consteladas, propõe uma nova ordem do pensamento. Fenollosa se pergunta "em que sentido versos escritos sob a forma de hieróglifos visíveis podem ser tidos por verdadeira poesia?", considerando que
Aparentemente, talvez, a poesia que, tal como a música, é uma arte do tempo, entretecendo suas unidades através de sucessivas impressões sonoras, dificilmente poderia assimilar um meio de comunicação verbal que consiste, em grande parte, de apelos semipictóricos ao olho. [FENOLLOSA, 1977, p. 120]
Embora não sejam exatamente "hieróglifos", as "miragrafias", como chamadas por Fabbrini, nos oferecem, de algum modo, uma resposta a essa pergunta. Fazendo outra vez circular a surpresa entre significante e significado - um significante sempre por vir, potência, portanto, de significados sempre múltiplos -, a artista nos oferece uma transferência de tempo da obra para o consumidor [em suas palavras: "o tempo se lança do símbolo de volta para a vida" [SCHENDEL, 1996 , p. 256]]: sua arte se dá no tempo, como a poesia, 
mas não de maneira sucessiva, e sim circular.

Mira nos permite experimentar, da escritura, seu

avesso, fazendo o espectador submeter-se a ele, "entrar no planetarium onde suas composições/ se suspendem desenhos estelares", ouvir o gorjeio desse "pássaro de avessos" a relativizar seus "haicais absolutos"; permite-nos, enfim, entrar na dobra de sua escritura, onde a ausência da palavra é eloquente, e encontrar em seus Objetos uma potente desescrita.

\section{NOTAS}

1 Este artigo foi escrito com o auxilio da bolsa de pesquisa de doutorado do CNPq.

2 Esta análise de Tania Rivera não refere-se ao trabalho de Mira Schendel; antes, refere-se ao trabalho da artista Helena Trindade, e consta no catálogo de uma exposição dela. Achamos, todavia, adequado inserir esta análise aqui. 


\section{REFERÊNCIAS}

BENJAMIN, Walter. Experiência e pobreza. In BENJAMIN, Walter. Magia, técnica, arte e polífica. Tradução de Sérgio Rouanet. São Paulo: Brasiliense, 1994.

CAMPOS, Haroldo de. Entrevista a Sônia Salzstein. In SALZSTEIN, Sônia (org.). no vazio do mundo: Mira Schendel. São Paulo: Marca d'Água, 1996.

CAMPOS, Haroldo de. da fenomenologia da composição à matemática da composição. In CAMPOS, Augusto de; CAMPOS, Haroldo de; PIGNATARI, Décio (orgs.). Teoria da poesia concreta: textos críticos e manifestos 1950-1960. Cotia: Ateliê Editorial, 2006.

FABBRINI, Ricardo Nascimento. Miragrafias. Folha de S. Paulo. Jornal de resenhas. 13 de abril de 2002. Disponível em https://www 1. folha.uol.com.br/fsp/resenha/rs 1304200210.htm, acesso em 05/03/2021.

FENOLLOSA, Ernest. Os caracteres da poesia chinesa como instrumento para a poesia. In CAMPOS, Haroldo (org.). Ideograma: lógica, poesia, linguagem. Textos traduzidos por Heloysa de Lima Dantas. São Paulo: Cultrix; Editora da Universidade de São Paulo, 1977.

FLUSSER, Vilém. Indagações sobre a origem da língua. In SALZSTEIN, Sônia (org.). no vazio do mundo: Mira Schendel. São Paulo: Marca d'Água, 1996.

MARQUES, Maria Eduarda. O lugar da pintura na obra de Mira Schendel. In Mira Schendel pintora. Catálogo de exposição. Instituto Moreira Salles, 2011.

RIVERA, Tania. A casa da letra. In TRINDADE, Helena. LIVROs. Rio de Janeiro: Contra Capa, 2009.

SALZSTEIN, Sônia (org.). no vazio do mundo: Mira Schendel. São Paulo: Marca d'Água, 1996.

SCHENDEL, Mira. Sem título. In SALZSTEIN, Sônia (org.). no vazio do mundo: Mira Schendel. São Paulo: Marca d'Água, 1996.

TRINDADE, Helena. Poética da letra. In SARAIVA, Alberto (org.). Poesia visual. Rio de Janeiro: F10 Editora; Oi Futuro, 2013.

Revista Poiésis, Niterói, v. 23, n. 39, p. 155-169, jan./jun. 2022. [DOl: hitps://doi.org/10.22409/poiesis.v23i39.49097] 